\title{
SOLO CITY GALLERY \\ Berpendekatan Architecture Post Modern
}

\author{
Miftakhul Ahyar \\ Program Studi Arsitektur, Fakultas Teknik, Universitas Tunas Pembangunan \\ miftakul9ahyar@gmail.com \\ Indro Sulistyanto \\ Program Studi Arsitektur, Fakultas Teknik, Universitas Tunas Pembangunan \\ indrosulistyanto@yahoo.co.id \\ Rully \\ Program Studi Arsitektur, Fakultas Teknik, Universitas Tunas Pembangunan \\ rullystmt@gmail.com
}

\begin{abstract}
Abstrak
City Gallery adalah tempat/ruang yang digunakan sebagai memamerkan karya dan budaya dalam bentuk dan penataan secara estetis. Galeri bukan saja digunakan sebagai pusat hiburan, melainkan sebagai pengembang wawasan dan edukasi setiap pengunjung. Solo City Gallery dapat diartikan sebagai tempat/ruang yang mempresentasikan potensipotensi kota (sejarah, kebudayaan, pariwisata, industri, tata kota, dll) dalam skala kecil dan lengkap yang berpendekatan arsitektur post modern. Konsep post modern yang kontekstual bagi budaya pembangunan Indonesia lekat dengan tujuan promosi pariwisata. Seni tempat bangunan banyak merujuk kembali pada masa lampau. Adanya gejala eklektisme yang gencar dan terbuka tampak jelas. Semua itu dilakukan atas nama pembangunan yang beridentitas lokal unsur yang dibubuhkan sebagai bungkus bangunan, berasal dari sejarah lokal yang komunikatif, realisasi sosial arsitektur Indonesia tidak bisah lepas dari konteks masyarakat. Struktur sosial budaya yang membentuk batasan perancangan arsitekturalnya masih samar. Kesamaan ini berkait erat dengan modernisasi sikap hidup di satu pihak, dan pertumbuhan ekonomi yang terus berlangsung tetapi terpusat.
\end{abstract}

Kata kunci: Galeri Kota, Solo, Post Modern

\begin{abstract}
City Gallery is a place / space that is used as a showcase of work and culture in aesthetic form and arrangement. The gallery is not only used as an entertainment center, but as a developer of insight and education for every visitor. Solo City Gallery can be interpreted as a place / space that presents the potential of the city (history, culture, tourism, industry, urban planning, etc.) on a small and complete scale with a close post modern architecture. The concept of post modern which is contextual for Indonesia's development culture is closely related to the purpose of tourism promotion. The art of building refers much back to the past. The existence of intense and open eclectic symptoms is evident. All of this was done in the name of development which identified local elements affixed as building packages, originating from communicative local history, social realization of Indonesian architecture could not be separated from the context of society. The socio-cultural structure that forms the boundaries of architectural design is still vague. This similarity is closely related to the modernization of life attitudes on the one hand, and ongoing but centralized economic growth.
\end{abstract}

Keywords: City Gallery, Solo, Post Modern 


\section{PENDAHULUAN}

\subsection{Latar Belakang}

"Sala" adalah satu dari tiga dusun yang dipilih oleh Sunan Pakubuwana II atas saran dari Tumenggung Hanggawangsa, Tumenggung Mangkuyudha, serta komandan pasukan Belanda, J.A.B. van Hohendorff, ketika akan mendirikan istana baru, setelah perang suksesi Mataram terjadi di Kartasura. Nama Sala/Solo lebih merujuk kepada penyebutan umum yang dilatar belakangi oleh aspek kultural. Seiring belanda yang salah melafalkan kata Sala, maka Solo semakin sering digunakan. Dan kata Solo pun menjadi semakin dan sangat populer ketika Eyang Gesang menciptakan lagu keroncong yang berjudul "Bengawan Solo", lagu yang populer sampai-sampai diterjemahkan ke dalam 7 bahasa.

Sekarang orang-orang luar kota Solo baik dalam maupun luar negeri lebih familiar dengan kata Solo. Event-event pariwisata dan budaya pun menggunakan nama Solo, seperti SIEM (Solo International Ethnic Music), SIPA (Solo International Performing Art), SBC (Solo Batik Carnival), Solo Menari, dan lain sebagainya. Project and development pun semakin memperkukuh nama ini, seperti Solo Paragon dan Solo Center Point. Nama resmi dan administratif kota Solo. semua instansi pemerintahan, sekolah, dan gedung pelayanan masyarakat menggunakan nama Surakarta. kata Sala dan Solo sendiri hanya merupakan nama lain dari Surakarta, dan bukan nama resmi.

Beberapa kota besar di Indonesia sudah memiliki bangunan galeri seperti di Bandung, Jakarta, Malang, dan Semarang. Kota Surakarta yang terus berkembang menjadi kota yang lebih maju sudah seharusnya memiliki bangunan galeri. Gedung galeri dapat digunakan sebagai fasilitas informasi sekaligus promosi mengenai potensi pariwisata dan kebudayaan. Khususnya Kota Surakarta memiliki potensi industri kreatif, galeri kota dapat memamerkan karya industri kreatif yang tersebar di Kota Surakarta. Berbagai macam hasil karya industri seperti batik, gerabah, mebel kayu, dan lukisan dapat berkumpul dan ditemukan di satu tempat yaitu di Galeri Kota. Galeri kota selain tempat untuk memamerkan karya industri juga dapat dijadikan tempat tujuan wisatawan saat berkunjung ke Kota Surakarta. Seperti Singapore City Gallery The URA Centre yang memiliki aktivitas menghubungkan berbagai komunitas, perencanaan jangka panjang kawasan, memfasilitasi pembangunan dan kebutuhan bisnis, membuat ruang terbuka yang hidup, dan menyenangkan, mempromosikan arsitektural dan urban desain. 
Galeri adalah tempat/ruang yang digunakan sebagai memamerkan karya dan budaya dalam bentuk dan penataan secara estetis. Galeri bukan saja digunakan sebagai pusat hiburan, melainkan sebagai pengembang wawasan dan edukasi setiap pengunjung. Berdasarkan penjelasan galeri di atas, galeri kota dapat diartikan sebagai tempat/ruang yang mempresentasikan potensi-potensi kota (sejarah, kebudayaan, pariwisata, industri, tata kota, dll) dalam skala kecil dan lengkap. Galeri kota dapat memamerkan potensi kota dari masa lalu, sekarang, dan masa yang akan dating yang berpendekatan arsitektur post modern. Konsep post modern yang kontekstual bagi budaya pembangunan Indonesia lekat dengan tujuan promosi pariwisata. Seni tempat bangunan banyak merujuk kembali pada masa lampau. Adanya gejala eklektisme yang gencar dan terbuka tampak jelas. Semua itu dilakukan atas nama pembangunan yang beridentitas lokal unsur yang dibubuhkan sebagai bungkus bangunan, berasal dari sejarah lokal yang komunikatif, realisasi sosial arsitektur Indonesia tidak bisah lepas dari konteks masyarakat. Struktur sosial budaya yang membentuk batasan perancangan arsitekturalnya masih samar. Kesamaan ini berkait erat dengan modernisasi sikap hidup di satu pihak, dan pertumbuhan ekonomi yang terus berlangsung tetapi terpusat.

\subsection{Rumusan Masalah}

Bagaimana merencanakan dan merancang Solo City Gallery yang mencerminkan Kota Surakarta dimasa mendatang.

\subsection{Tujuan}

Tujuan pembahasan adalah menyusun konsep Solo City Gallery sebagai wadah yang mampu mempresentasikan perkembangan kota dari masa lalu, sekarang, dan masa yang akan datang.

\section{METODE PENELITIAN}

Metode pembahasan yang digunakan dalam penyusunan jurnal arsitektur dengan judul Solo City Gallery ini adalah metode deskriptif. Metode ini memaparkan, menguraikan, dan menjelaskan mengenai design requirement (persyaratan desain) dan design determinant (ketentuan desain) terhadap perencanaan dan perencangan tersebut.

Berdasarkan design requirement dan design determinant inilah nantinya akan ditelusuri data yang diperlukan. Data yang terkumpul kemudian akan dianalisa lebih mendalam sesuai dengan kriteria yang akan dibahas. Dari hasil penganalisaan inilah nantinya akan didapat suatu kesimpulan, batasan dan juga anggapan secara jelas mengenai perencanaan dan perancangan Solo City Gallery.

Hasil kesimpulan keseluruhan nantinya merupakan konsep dasar yang digunakan dalam perencanaan dan perancangan Solo City Gallery. 
a. Pengumpulan data, yaitu pengumpulan data-data sekunder untuk bekal survey lapangan guna menghasilkan data primer dan eksplorasi data sekunder melalui literatur dan wawancara.

b. Kompilasi data, yaitu menyusun, memilah-milah dan mengklarifikasikan data kedalam bagian-bagian yang relevan.

c. Analisis data, yaitu pengkajian data dan informasi yang didapatkan dengan pencarian data yang akan digunakan dalam penyusunan konsep perencanaan dan perancangan.

d. Sintesis, yaitu menggabungkan hasil analisis data ke dalam konsep perencanaan dan perancangan Tugas Akhir yang akan dilanjutkan dalam tahap studio Tugas Akhir.

\section{PEMBAHASAN}

A. Lokasi

Dasar pertimbangan untuk pemilihan lokasi sebagai berikut:

1. Sesuai dengan Rencana Tata Ruang Wilayah (RTRW) Kota Surakarta, yaitu pada fungsi pelayanan pariwisata.

2. Persyaratan luas tapak yang dapat mendukung bangunan Solo City Gallery.

B. Tapak

a. Pemilihan tapak Solo City Gallery di Surakarta ini menggunakan kriteria sebagai berikut.
1) Keamanan
2) Lingkungan
3) Pencapaian
4) Daya kenal

5) Potensi lahan

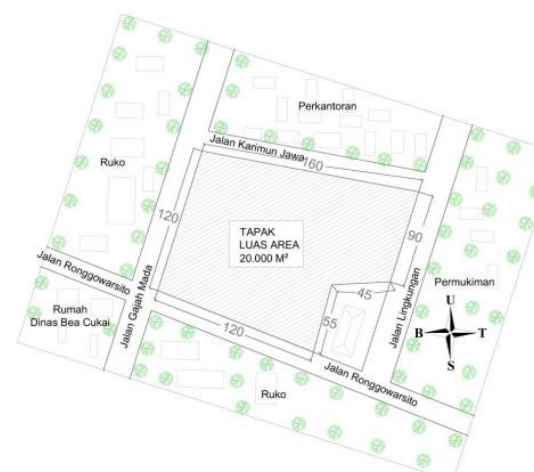

Gambar 1 Tapak Solo City Gallery

(Sumber: Data Pribadi)

Terletak pada Jl. Ronggowarsito, Jl. Gajah Mada dan Jl. Karimun Jawa, Banjarsari, Kota Surakarta, memiliki luas $20.000 \mathrm{~m}^{2}$, lokasi sekitar terdapat Monumen Pers Nasional, Grand Orchid Hotel Solo dan pencapaian yang mudah. Batas tapak:
a. Sebelah Timur : Sekolah Dasar Negeri Beskalan

b. Sebelah Selatan : Jalan Ronggowarsito

c. Sebelah Barat : Jalan Gajah Mada

d. Sebelah Utara : Jalan Karimun Jawa

C. Pengolahan Tapak

a) Pencapaian

Adapun hal-hal yang perlu dipertimbangkan dalam pencapaian, adalah sebagai berikut.

1.Arah datangnya pengunjung baik yang memakai kendaraan maupun yang berjalan kaki.

2.Kemudahan akses masuk maupun akses keluar bagi pengunjung Solo City Gallery baik pejalan kaki maupun yang memakai kendaraan. 
3.Pertimbangan keamanan pengunjung untuk akses masuk maupun keluar.

Untuk pintu masuk utama ME memiliki kriteria sebagai berikut.

a) Mudah di lihat dan mudah di capai pengunjung.

b) Menghadap langsung ke arah jalan utama atau menghadap ke arah jalan yang mempunyai intensitas tertinggi untuk memudahkan sirkulasi kendaraan pengunjung dan mudah dicapai dari jalur kendaraan umum.

c) Kelancaran lalu lintas dan keamanan pengunjung tanpa ada gangguan dengan kegiatan sirkulasi di dalam tapak.

Sedang SE adalah pencapaian sirkulasi keluar masuk pengelola atau memasukkan barang (louding unloadding), memiliki kriteria sebagai berikut.

a) Kegiatan yang terjadi tidak mengganggu pengunjung baik secara sirkulasi maupun pandangan.

b) Mendukung fungsi kegiatan bagi pengelola maupun service.

c) Terletak bukan di jalan utama.

d) Tidak menyebabkan kemacetan sirkulasi di dalam site.

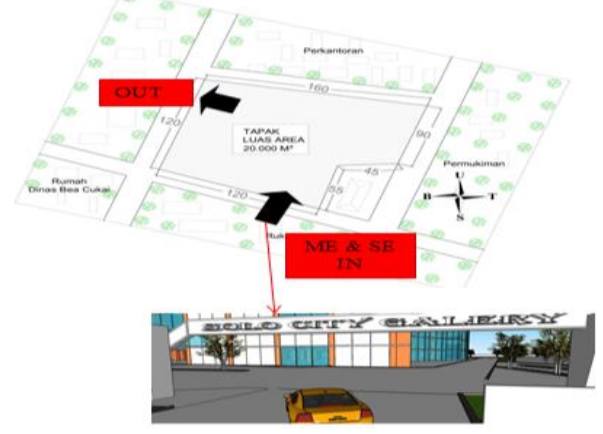

Gambar 2 Pencapaian ME dan SE

(Sumber: Data Pribadi) b) Orientasi

Berdasarkan kriteria pemilihan tapak, tapak didukung oleh view yang bagus yaitu menghadap kejalan Ronggowarsito sebagai orientasi primer dan orientasi sekunder menghadap ke jalan Gajah mada dan jalan Lingkungan.

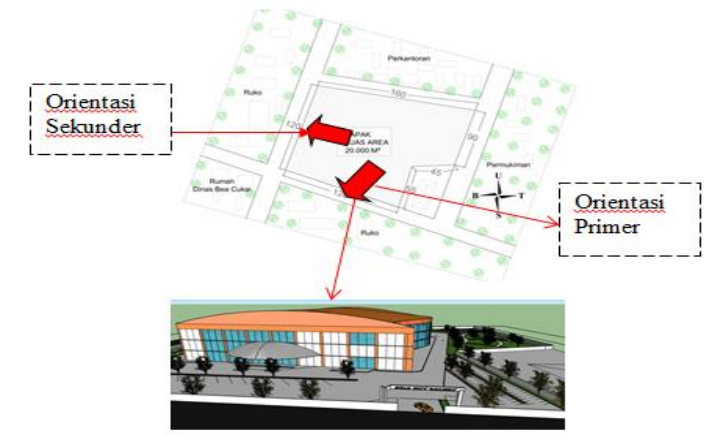

Gambar 3 Orientasi Terhadap Bangunan

(Sumber: Data Pribadi)

\section{c) Titik Tangkap}

Berdasarkan kriteria pemilihan tapak, titik tangkap didukung oleh letak tapak yang strategis yaitu berada pada jalan Gajah mada, dan dengan kondisi jalan yang padat dengan jumlah pengamat yang lebih banyak maka poin of interest menghadap keperempatan.

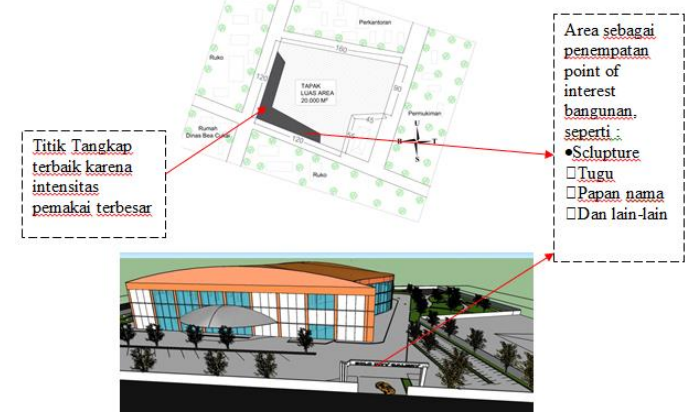

Gambar 4 Titik Tangkap

(Sumber: Data Pribadi) 


\section{d) Kebisingan}

Berdasarkan kriteria pemilihan tapak, yang berdekatan dengan pusat pendukung Solo City Gallery, dan dengan intensitas jalan yang cukup tinggi, maka tapak tidak dapat terhindar dari kebisingan, yaitu dari kebisingan jalan yang cukup tinggi, dan pemukiman, untuk itu tapak perlu pengantisipasian terhadap kebisingan.

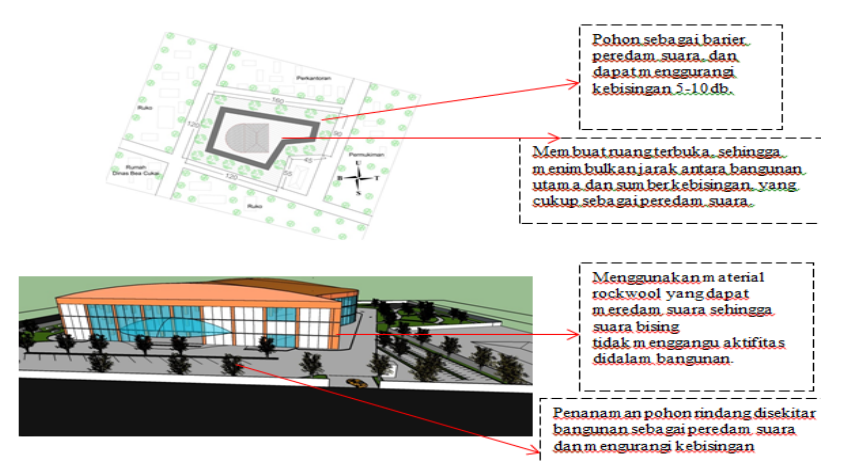

Gambar 5 Kebisingan

(Sumber: Data Pribadi)

e) Matahari dan Angin

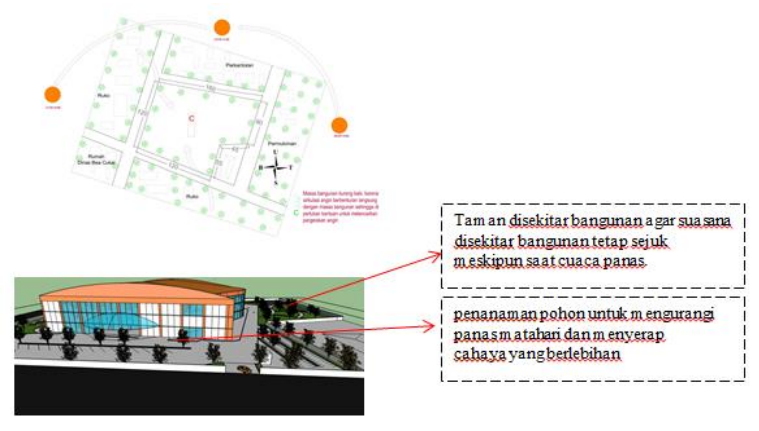

Gambar 6 Matahari dan Angin

(Sumber: Data Pribadi)

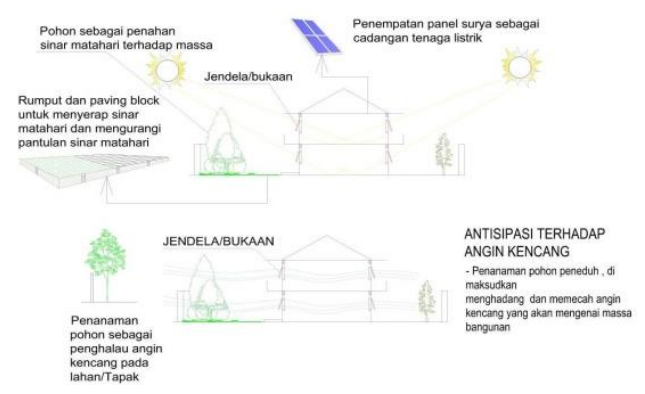

Pengantisipasiannya:

f)

Hubungan Ruang

1) Kegiatan Penerimaan

\begin{tabular}{|c|l|c|l|}
\hline Kelompok ruang & \multicolumn{1}{|c|}{ Jenis ruang } & $\begin{array}{c}\text { Hubungan } \\
\text { ruang }\end{array}$ & Dihubungkan \\
\hline \multirow{5}{*}{ Penerimaan } & 1. Entrance hall & $1-2$ & Partisi Kaca+pintu \\
& 2. Lounge & $2-3$ & Partisi Kacatpintu \\
& 3. R. Informasi & $3-4$ & Partisi Kacatpintu \\
& 4. Penitipan Barang & $4-5$ & Koridor \\
& 5. Tiket Box & $5-6$ & Koridor \\
& 6. Lavatory & $1-6$ & Koridor \\
\hline
\end{tabular}

2) Kegiatan Utama

\begin{tabular}{|c|l|c|l|}
\hline Kelompok ruang & \multicolumn{1}{|c|}{ Jenis ruang } & $\begin{array}{c}\text { Hubungan } \\
\text { ruang }\end{array}$ & \multicolumn{1}{|c|}{ Dihubungkan } \\
\hline \multirow{5}{*}{ Utama } & 1. Virtual & $1-2$ & Koridor \\
& 2. Pameran Temporer & $2-3$ & Koridor \\
& 3. Exhibition & $3-4$ & Koridor \\
& 4. Central Model Maket & $4-5$ & Koridor \\
& 5. Maket & $5-6$ & Partisi + pintu \\
& 6. Disain Perkotaan & $6-7$ & Partisi Kaca+pintu \\
& 7. Audio Visual & $7-8$ & Koridor \\
& 8. Study Area buku flip & $8-9$ & Partisi Kaca+pintu \\
& 9. Ruang penyimpanan & & \\
& 10. Perpusatakaan & $9-10$ & Partisi Kaca+pintu \\
& 11. Pusat Pendidikan & $9-10$ & Partisi Kaca+pintu \\
& Anak & & \\
\hline
\end{tabular}

3) Kegiatan Pengelola

\begin{tabular}{|c|l|c|l|}
\hline Kelompok ruang & \multicolumn{1}{|c|}{ Jenis ruang } & $\begin{array}{c}\text { Hubungan } \\
\text { ruang }\end{array}$ & \multicolumn{1}{|c|}{ Dihubungkan } \\
\hline \multirow{5}{*}{ Pengelola } & 1. Ruang Tamu & $1-2$ & Partisi Kaca+pintu \\
& 2. Ruang Pimpinan & $2-3$ & Partisi Kaca+pintu \\
& 3. Ruang Staf & $3-4$ & Partisi Kaca+pintu \\
& 4. Ruang Rapat & $4-5$ & Dinding+pintu \\
& 5. Pantry & $5-6$ & Dinding+pintu \\
& 6. Lavatory & 6 & Dinding+pintu \\
& & &
\end{tabular}

4) Kegiatan Servis

\begin{tabular}{|c|l|c|l|}
\hline Kelompok ruang & \multicolumn{1}{|c|}{ Jenis ruang } & $\begin{array}{c}\text { Hubungan } \\
\text { ruang }\end{array}$ & \multicolumn{1}{|c|}{ Dihubungkan } \\
\hline \multirow{5}{*}{ Servis } & 1. Ruang Pompa & $1-2$ & Dinding +pintu \\
& 2. Ruang AHU & $2-3$ & Dinding +pintu \\
& 3. Ruang ME & $3-4$ & Dinding +pintu \\
& 4. Ruang Genset & $4-5$ & Dinding+pintu \\
& 5. Pantry & $5-6$ & Dinding+pintu \\
& 6. Lavatory & 6 & Dinding+pintu \\
\hline
\end{tabular}

g) Sistem Akustik

Guna mendapatkan system akustik yang baik, maka perlu diperhatikan konstruksi 
dinding, lantai dan plafond agar dapat mencapai suara yang baik.

\section{1)Dinding}

Dasar pertimbangan :

a) Dapat menahan distorsi gelombang elektro magnet dari luar.

b)Dapat mereduksi suara yang bising dari dalam dan luar bangunan.

c) pantulan dinding : merupakan bidang masiv yang akan memantulkan jika tidak terdapat bahan yang bisa menyerap gelombang cahaya pada dinding tersebut

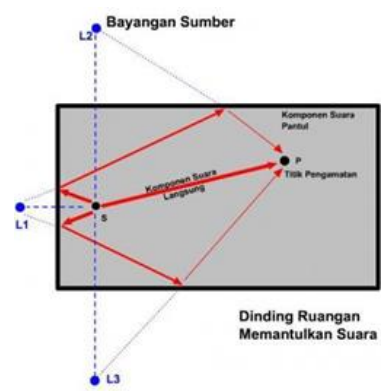

Gambar 7 Gambar Akustik Dinding

(Sumber: Data Pribadi)

2) Lantai

Dasar pertimbangan :

a) Fungsi dan kegiatan dalam ruang

b) Persyaratan ruang

Untuk ruang pamer dibutuhkan konstruksi lantai yang spesifik agar dapat menyerap bunyi, sehingga tidak menggangu ruang lain.
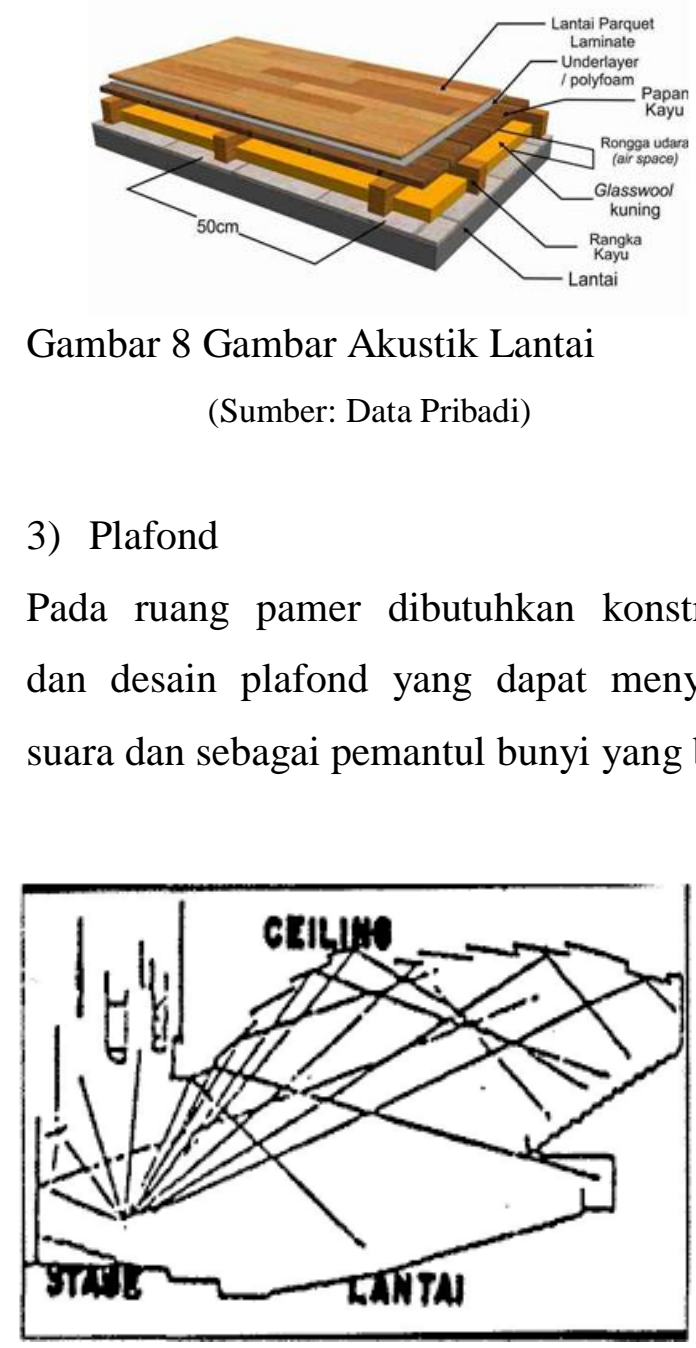

Gambar 8 Gambar Akustik Lantai

(Sumber: Data Pribadi)

3) Plafond

Pada ruang pamer dibutuhkan konstruksi dan desain plafond yang dapat menyerap suara dan sebagai pemantul bunyi yang baik.

Gambar 9 Gambar Akustik Plafond

(Sumber: Data Pribadi)

h) Zonning

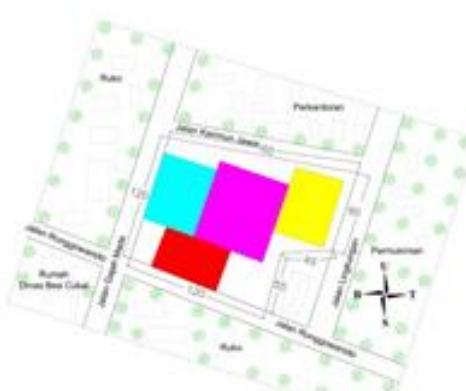

Gambar 10 Zonning Horizontal

(Sumber: Data Pribadi) 


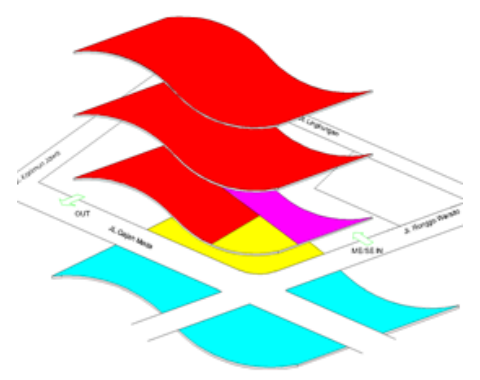

Gambar 11 Zonning Vertikal

(Sumber: Data Pribadi

i) Penampilan Bangunan

Sesuai dengan konsep ungkapan citra arsitektur Post Modern. Maka penampilan bangunan ditujukan sesuai pada konsep yang telah diterapkan pada penampilan bangunan.

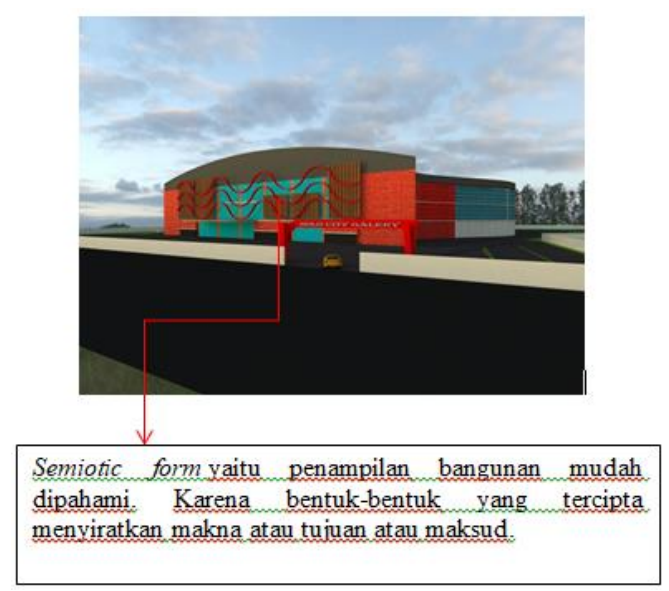

Gambar 12 Penampilan Bangunan (Sumber: Data Pribadi)

\section{KESIMPULAN/RINGKASAN}

Solo City Gallery dapat diartikan sebagai tempat/ruang yang mempresentasikan potensipotensi kota (sejarah, kebudayaan, pariwisata, industri, tata kota, dll) dalam skala kecil dan lengkap yang berpendekatan arsitektur post modern. Yang dapat dilihat dari bentuk fasad bangunan yang menggunakan material kaca dan kayu, dimana kaca sebagai material yang memberi kesan modern dan material kayu yang memberi kesan tradisional.

\section{UCAPAN TERIMA KASIH}

1. Kepada Ibu Ir. Eny Krisnawati, M.Si., selaku Dekan Fakultas Teknik Universitas Tunas Pembangunan Surakarta

2. Kepada Bapak A. Bamban Yuuwono ST., MT, selaku Ketua Progdi Arsitektur Fakultas Teknik Universitas Tunas Pembangunan Surakarta

3. Kepada Bapak Ir. Indro Sulistyanto, MT. selaku dosen Pembimbing Utama

4. Kepada Bapak Rully, ST.,MT. selaku dosen Pembimbing Pembantu

5. Kepada Ibu Ir. Eny Krisnawati, M.Si., selaku dosen penguji 1

6. Kepada Ibu Ir. Danarti Karsono, MT. selaku dosen Penguji 2

7.Kepada Kedua Orang Tua dan Seluruh anggota keluarga saya

8. Kepada seluruh rekan angkatan 2015 khususnya teman-teman yang rela meluangkan waktu untuk membantu pengerjaan tahap desain

9. Semua pihak yang tidak dapat disebutkan satu per satu, yang telah ikut membantu secara langsung maupun tidak langsung 


\section{DAFTAR PUSTAKA}

Harry Carter, A History of Oxford University

Press, (Oxford: Clarendon Press, 1975)

Lawrence Cahoone. 1995. From Modernism to

Postmodernism: An Anthology. Oxford:

Blackwell Publisher, 469-480

sharp dennis the illustrated encyclopedia of architect and architecture. New York Quatro Publishing 1991

Cyril M. Harris. 2005 Dictionary of Architecture and Construction, McGrawHill Arsitektur setelah Modernisme. 1996 New York: Thames \& Hudson Walter Gropius," Programme of the staatloches Bauhaus in Weimar" (1919), dalam Programmes and Manifestos on TwentiethCentury Architecture,ed. Ulrich Conrads, terj. Michael Bullock (London: Lund Humphries, 1970), Hal. 25.

Charles Moore, dalam Conversations with Architecs, ed. John Cook Heeinrich dan Klotz (New York: Praeger, 1973), hal. 243.

Howard Fox, "Avant-Garde in the Eighties", dalam The Post-Avant- Garde: Painting in the Eighties, ed. Charles Jencks (London: Academy Editions, 1987), hal. 29-30. 